\title{
Musealizar el pasado y el presente de la violencia. Un estudio de las percepciones de los visitantes del Museo Casa de la Memoria de Medellín*
}

JULIE LAVIELLE**

Artículo recibido: 23 de agosto de 2019

Artículo aceptado: 8 de octubre de 2019

Doi: https://doi.org/10.12804/revistas.urosario.edu.co/desafios/a.8186

Para citar este artículo: Lavielle, J. (2020). Musealizar el pasado y el presente de la violencia. Un estudio de las percepciones de los visitantes del Museo Casa de la Memoria de Medellín. Desafios, 32(2), 1-39. https://www.doi.org/10.12804/revistas.urosario.edu.co/desafios/a.8186

\section{Resumen}

Este artículo tiene como propósito entender cómo la población percibe los relatos museológicos sobre el conflicto armado colombiano en un contexto en el que el conflicto continúa su vigencia. Esta problemática se aborda a partir de los resultados de un estudio de campo realizado a los visitantes del Museo Casa de la Memoria de Medellín. La metodología es cualitativa y cuantitativa, e incluye cuestionarios, observaciones de visitas

\footnotetext{
* Este artículo se realizó con el patrocinio del Labex Lespassés dans le présent. En este marco, se benefició de la ayuda otorgada por el Estado francés a través de la Agence Nationale de la Recherche (ANR), siguiendo con su programa Investissement d'avenir, que lleva la referencia ANR-11-LABX-0026-01.

La autora quiere agradecer a Malena Bastías Sekulovic y a Fabián Correa Bohórquez por sus revisiones al presente artículo.

** Institut des Sciences sociales du Politique (Nanterre, Francia). Correo electrónico: julie. lavielle@gmail.com. oRCID: http://orcid.org/0000-0001-7311-9019
} 


\title{
2 I JULIE LAVIELLE
}

y entrevistas con el público. El artículo muestra que la relación de los visitantes con el relato del museo está orientada por varios factores: la relación personal con el conflicto armado, las opiniones politicas y las referencias culturales presentes en la sociedad colombiana, asi como, también, por los roles sucesivos que asumen durante su visita. Finalmente, en el artículo se pone en evidencia la relación ambigua de los visitantes con la violencia: por un lado la condenan, pero por otro, justifican o aceptan su uso para perseguir objetivos que estiman justos.

Palabras clave: posconflicto; memoria; museo; visitas a museos; Colombia; Medellin.

\section{Turning Violence's Past and Present into a Museum. A Study of Visitors' Perceptions of Medellin's Museo Casa de la Memoria}

\begin{abstract}
The aim of this article is to capture how museum narratives of the Colombian armed conflict are perceived in the context of an ongoing conflict. The issue is discussed on the basis of results of an investigation which was carried out with visitors of the Museo Casa de la Memoria in Medellin (questionnaires, observations of visits, interviews with visitors). The article argues that the relation between visitors and the museum narrative is guided by several factors: personal relation with the armed conflict, political opinions and cultural references present in Colombian society, and by successive roles visitors assume during their visit. Finally, it demonstrates visitors' ambiguous relationship with violence: even though they condemn violence, they justify or accept the use of violence to pursue goals they consider just.
\end{abstract}

Keywords: Post-conflict; memory; museum; museum visits; Colombia; Medellin. 


\title{
Musealizar o passado e o presente da violência. Um estudo das perceções dos visitantes do Museo Casa de la Memoria de Medellín
}

\begin{abstract}
Resumo
Este artigo tem como propósito entender como os relatos museológicos sobre um conflito armado colombiano são percebidos pela população em um contexto onde o conflito continua sua vigência. Esta problemática é abordada a partir dos resultados de um estudo de campo realizado sobre os visitantes do Museo Casa de la Memoria de Medellin. A metodologia é qualitativa e quantitativa: mobiliza questionários, observações de visitas e entrevistas com o público. O artigo mostra que a relação dos visitantes com o relato do museu é orientada por vários fatores: a relação pessoal com o conflito armado, as opiniões politicas e as referências culturais presentes na sociedade colombiana, assim como pelos roles sucessivos que assumem durante sua visita. Põe finalmente em evidência uma relação ambigua dos visitantes com a violência: enquanto os visitantes a condenam, justificam ou aceitam seu uso para perseguir objetivos que se estimam justos. Palavras-chave: Pós-conflito; memória; museu; visitas a museus; Colômbia; Medellin.
\end{abstract}

\section{Introducción}

Desde los años noventa, mientras la figura de la víctima fue cobrando cada vez más importancia en el espacio público (Fassin \& Rechtman, 2007), los museos de la memoria y los memoriales se han ido multiplicando (Sodaro, 2017; Williams, 2007; Young, 1993). En América Latina, diversos espacios que ponen en escena el pasado violento y doloroso de las sociedades se crearon después de las dictaduras del Cono Sur (Jelin \& Langland, 2003) o de las guerras civiles (Salamanca, 2015; Delacroix, 2014). Dentro de este movimiento hacia la construcción de lugares que narran el pasado violento, Colombia se caracteriza por su particularidad, dado que muchos de estos lugares se han construido en medio del conflicto. Ana Guglielmucci y Loreto López enfatizan en la heterogeneidad de los actores que encabezan su 
construcción (iglesias, asociaciones locales y nacionales, ONG, alcaldías, Estado) y de los discursos que se desarrollan en estos lugares (denuncia de la responsabilidad de entes públicos, homenaje a las víctimas, llamado a la reconciliación y a la convivencia) (Guglielmucci \& López, 2009). En efecto, como resultado de la implementación de mecanismos de justicia transicional en Colombia (Lecombe, 2014), muchas asociaciones de víctimas y organizaciones de la sociedad civil se fortalecieron a través de la reconstrucción de la memoria histórica, mientras que el Estado colombiano empezó a implementar políticas públicas enfocadas en la construcción de un relato público sobre el conflicto armado (Jaramillo Marín, 2010). De esta manera, la memoria se ha vuelto una meta alrededor de la cual varios actores se encuentran, dialogan, se disputan o colaboran.

Todos comparten la convicción de que recordar el pasado permite no repetirlo y que hacer memoria es un medio para construir la paz. En 2016, el director del Centro Nacional de Memoria Histórica e historiador, Gonzalo Sánchez (2014), habló del "soplo transformador de la memoria" que se siente en el territorio colombiano (p. 2). Sin embargo, varias dinámicas políticas observadas en numerosos países muestran los límites de la capacidad de transformación social de la memoria. En Europa, aunque la historia de las dos guerras mundiales se enseña bajo múltiples formas, el nacionalismo sube (Neumayer, 2012). En Brasil, la Comisión Nacional de la Verdad, que tuvo lugar en 2012, no impidió el retorno del autoritarismo en 2019 (Moura de Oliveira \& Veronese, 2019). En Colombia, el reconocimiento de las víctimas, institucionalizado con la Ley 1448 de 2011, y la creación del Centro Nacional de Memoria Histórica ha tenido resultados moderados: en 2016, los colombianos rechazaron el acuerdo de paz logrado entre el gobierno y la guerrilla de las FARC-EP y solo el $37 \%$ del censo salió a votar en este plebisicito. En un artículo publicado en 2018, Gonzalo Sánchez (2018) constata que “es todavía mucha la sociedad que no se siente interpelada con la violencia padecida en los entornos rurales, cuyas víctimas son anónimas para la percepción general" (p. 111). 
Diversos investigadores en ciencias sociales han empezado a mostrar que las políticas de memoria implementadas al salir de periodos de violencia proponen una versión descontextualizada y deshistorizada del pasado (David, 2017) y fortalecen el confinamiento nacionalista (Feldman, 2010). El límite del "soplo transformador" de la memoria ha sido documentado, pero los mecanismos que explican este límite han sido poco estudiados (Gensburger \& Lefranc, 2017). Este artículo tiene como propósito entender estos mecanismos a través del estudio de las apropiaciones sociales del relato sobre el pasado violento colombiano, elaborado por el Museo Casa de la Memoria de Medellín (MCM) cuya construcción se inició en 2011, y que se inauguró en 2013 por la Alcaldía. Cuestionar la existencia del poder "transformador" de los relatos expuestos dentro de los lugares de memoria es interesante en un país como Colombia en el que el conflicto armado tiene una vigencia de más de sesenta años y en el que la violencia se vive a diario. Acercarse a las percepciones del público de las exposiciones que relatan la violencia es crucial para entender la relación de los colombianos con la violencia pasada, la violencia presente y la construcción de la paz en el futuro. ¿Qué impacto tiene el hecho de vivir en un contexto de violencia respecto a la relación de la sociedad con la violencia pasada? ¿Qué pasa cuando el visitante sale de un museo que habla de la violencia y vuelve a una cotidianidad que es atravesada por ella? Para desarrollar esta reflexión, nos basaremos en el trabajo de investigación que hicimos sobre el público del MCM, en abril de 2015.

\section{Metodología de la investigación y bases de datos}

Varias fuentes y metodologías se movilizaron en esta investigación. La primera fuente es un cuestionario que distribuimos durante seis días en abril de 2015 (tres durante la semana, tres durante los fines de semana) a 131 visitantes cuando salían de la exposición permanente del Museo. Este cuestionario se enfocaba en las percepciones del público sobre el Museo y la exposición permanente. ${ }^{1}$ Es importante

1 El cuestionario figura como anexo al final del artículo. 


\section{6 / Julie Lavielle}

notar que el objetivo no era ver si los visitantes se acordaban "bien" de los elementos expuestos, sino entender qué es lo que recordaban y cómo habían vivido su experiencia de visita. Partimos de la hipótesis de que los visitantes no son una "hoja en blanco" sobre la cual el discurso del museo se imprime, sino que sus trayectorias biográficas y sus características sociales tienen un papel central en la apropiación del discurso. Por esta razón, una parte del cuestionario recogía varios datos sociológicos (sexo, edad, oficio, lugar de residencia, opiniones políticas y creencias religiosas). La segunda fuente de esta investigación es un corpus de veintidós entrevistas. La mayor parte de estas entrevistas se hicieron con grupos (parejas, amigos, familias), teniendo en cuenta un total de cuarenta y dos personas entrevistadas (veintidós mujeres, veinte hombres). Si bien las preguntas se orientaban de acuerdo a los mismos temas del cuestionario, el asunto de la presencia del conflicto armado colombiano dentro de las trayectorias biográficas de los visitantes tomó cada vez más fuerza en los relatos. La tercera fuente recogió las observaciones realizadas a varios visitantes durante su recorrido por la exposición. Finalmente, la cuarta fuente es una base de datos compartida por el MCM que reúne el perfil de trescientos veintitrés visitantes. Esta base se tomó del registro de las visitas de los meses de febrero, marzo, abril y mayo de 2015, y se usó para comprobar la representatividad de las personas que contestaron al cuestionario y que se entrevistaron.

Para iniciar nuestra reflexión, ponemos en evidencia el discurso polifónico de la sala de exposición permanente del MCM, al mostrar que este abre la posibilidad a una multiplicidad de interpretaciones sobre el conflicto armado colombiano y medellinense. A continuación, explicamos que, a pesar de esta apertura, los visitantes se remiten a ciertos valores y emociones. Luego, hacemos un énfasis en los múltiples filtros de percepción que enmarcan la visita al MCM y demostramos que los visitantes encuentran en este espacio lo que estaban dispuestos a encontrar. En la última parte del artículo, proponemos pistas de reflexión para entender la relación ambigua de los visitantes frente a la legitimidad y a la justificación de la violencia. 


\section{Un Museo abierto y polifónico}

El Museo Casa de la Memoria (MCM) es un lugar gratuito y abierto a todos. Por una parte, su público es heterogéneo, pues tiene orígenes geográficos (extranjeros, habitantes de la región y vecinos) y sociales (clases altas, medias y populares) diversos. Por otra parte, el relato de la exposición permanente procura dar cabida a múltiples interpretaciones del pasado violento colombiano.

\section{Un visitante joven, de clase media y vecino del museo}

En 2014, un año después de su apertura, se registraron 2961 visitantes (Museo Casa de la Memoria, 2017, 27), mientras que 63202 personas lo visitaron en 2018 (Museo Casa de la Memoria, 2018, 97). Aunque el número de visitantes sigue siendo bajo, si lo comparamos con las cifras del Museo de Antioquia que, para el año 2017 registró 265300 visitas (Museo de Antioquia, 2017, 36), o del Parque Explora, que registró 613527 visitantes en el 2018 (Parque Explora, 2018, 42), en los últimos años ha habido un creciente interés por el MCM. Así pues, podemos decir que el perfil del público del MCM es similar al público del Museo de Antioquia (Valle Florez, Giraldo Velásquez \& Zapata Aguirre, 2018, p. 30), es decir, un público joven, pues la categoría más numerosa de visitantes tiene entre 18 y 25 años, y está compuesto por un $40 \%$ de visitantes extranjeros (Museo Casa de la Memoria, 2018, p. 103). La base de datos compartida por el MCM para este estudio corrobora estos datos pues el $28 \%$ de los visitantes tiene entre $18 \mathrm{y}$ 25 años y la mitad de los visitantes son estudiantes.

El lugar de residencia permite indagar más a fondo el perfil sociológico del público del MCM. El 22\% de los visitantes no vive en Medellín, y, entre ellos, más de la mitad vive en Antioquia y menos del $1 \%$ son extranjeros. La proporción menor de extranjeros en esta muestra se puede explicar por su periodo: en 2015, el MCM no figuraba en el mapa distribuido por los puntos de información turística. Además, el número de turistas extranjeros crece durante los meses de verano, mientras que esta cifra se basa en los registros de febrero, marzo, abril 
y mayo. Finalmente, dentro de los visitantes que viven en Medellín, el $70 \%$ vive en un barrio de estrato 3 :

\section{Figura 1. Estrato del barrio de los visitantes que viven en Medellín} $N=253$ visitantes.

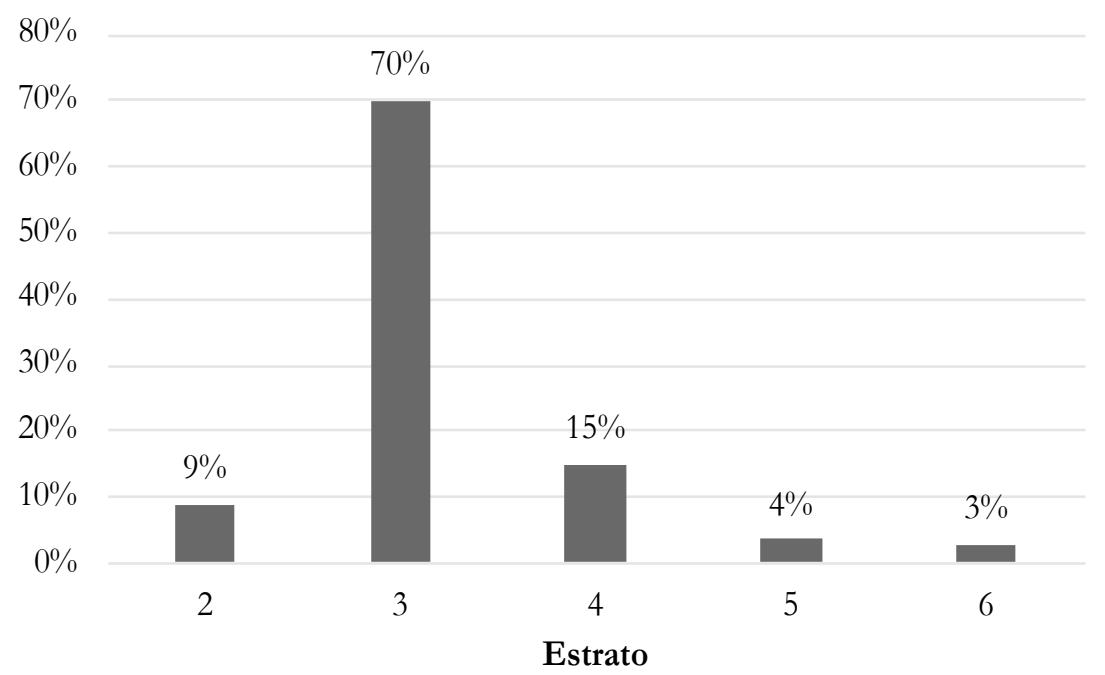

Fuente: Elaboración propia a partir de registro de MCM de febrero a mayo de 2015.

$\mathrm{Al}$ analizar estas cifras más desde cerca, nos damos cuenta de que un $26 \%$ de los visitantes vive en barrios cercanos al MCM. Finalmente, la edad promedio de los visitantes de esta muestra es de 23 años. Las características de las 131 personas que participaron en nuestra encuesta varían respecto de las registradas por el MCM. Si bien el público está compuesto por un $60 \%$ de mujeres en ambas muestras, las personas que contestaron nuestra encuesta son mayores, pues tienen una edad promedio de 26 años. En efecto, nuestro trabajo fue llevado a cabo durante los días de semana y de fines de semana. El público de los fines de semana está compuesto de empleados y no solo de estudiantes o de escolares, lo que hace aumentar la edad promedio de los visitantes. Esta temporalidad de aplicación de la encuesta explica otras diferencias: la parte del público que vive en los barrios vecinos del museo es menor (16\%) y el porcentaje de clase media, que vive en barrios lejanos o fuera de Medellín, es mayor. Sin embargo, el perfil sociológico del público de nuestra muestra es parecido a lo 
que observamos con la base de datos compartida por el MCM, pues más de la mitad del público vive en barrios de estratos 3 y 4 , y el número de visitantes perteneciente a las clases altas y bajas es bastante bajo.

Figura 2. Estrato del barrio de los visitantes que viven en Medellín

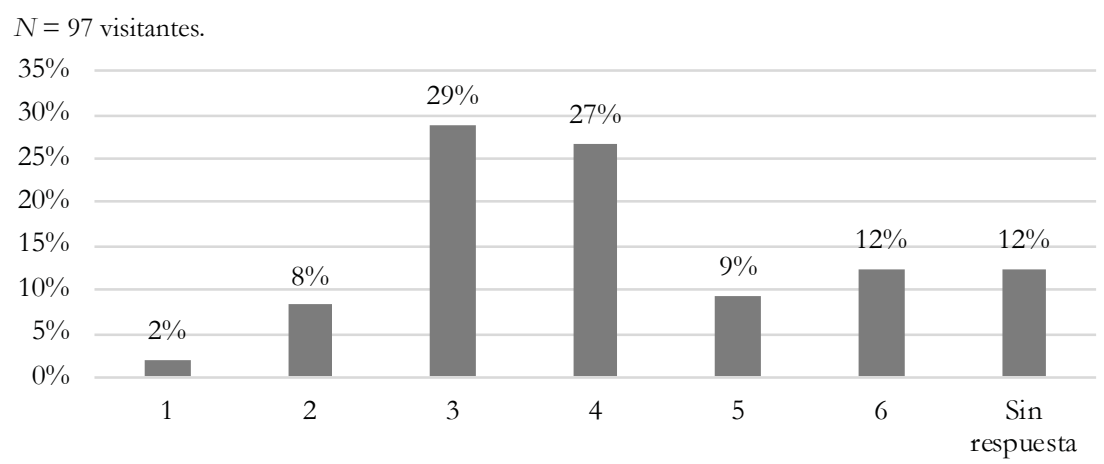

Estrato

Fuente: Elaboración propia a partir de nuestra encuesta en abril de 2015.

\section{Discurso histórico, discurso artístico, discurso testimonial}

El texto de introducción de la sala de la exposición permanente, cuyo nombre es "Medellín, memorias de violencia y de resistencia", hace énfasis en la pluralidad de voces que se expresan sobre la violencia. El museo se define como un portavoz de los diferentes puntos de vista que existen sobre el pasado (los puntos de vista de los testigos pasivos, de los actores sociales y políticos que denunciaron la violencia, pero también de los víctimarios) y afirma no querer difundir una versión sobre el pasado violento, pues "no existe una Verdad. No hay una historia completa". ${ }^{2} \mathrm{El}$ MCM asegura no imponer una visión oficial sobre el pasado porque quiere incluir la mayor cantidad posible de gente en su relato. Propone lo que Sophie Wahnich (2011) llama un "discurso social estándar". En efecto, la historiadora francesa explica que la mayoría de los museos de historia de las guerras son lugares de consenso

2 Texto que introduce la sala de exposición permanente. 


\section{0 / Julie LavielLe}

donde cada uno puede buscar e inventar su propio ritual de apaciguamiento, su ritual de duelo, su relación con el otro, su relación con la violencia y despertar su opinión crítica frente a la ideología o frente a una forma de guerra que no le conviene (Wahnich, 2011, p. 35).

En el MCM, este discurso estándar se despliega a través de cuatro ejes. El primer eje es una lectura del conflicto armado a partir de fechas, de cifras y de acontecimientos expuestos por varios mapas de Medellín y por una cronología interactiva. El segundo eje es testimonial; consiste en dieciocho pantallas de dos metros de altura que difunden testimonios audiovisuales de víctimas civiles del conflicto armado en Medellín y en Antioquia, así como de personalidades de izquierda y trece testimonios de audio que corresponden a trece hechos victimizantes. El tercer eje es simbólico; dieciséis mesas temáticas que tratan temas diversos (desplazamiento forzado, conflicto agrario, victimización de las mujeres, de los indígenas...) a través de metáforas: cinco videos que representan los conceptos de miedo, solidaridad, resiliencia, memoria y diversidad, así como varias pancartas que exponen definiciones hechas por niños sobre los conceptos de vida, muerte y desplazamiento, entre otros. Por último, el cuarto eje de lectura es artístico: se desarrolla a través de la exposición de fotografías de periodistas y de obras pictóricas sobre el conflicto armado.

La exposición permanente presenta múltiples lecturas del conflicto armado (al proponer una lectura simbólica, testimonial, artística y factual) así como sus correspondientes ángulos de análisis (en términos de construcción histórica de las desigualdades socio-económicas, de los acontecimientos que marcaron la historia del país, o a través de las palabras de un testigo, de una víctima, de un fotógrafo o de un artista). Esta superposición de lecturas tiene como consecuencia que ningún mensaje claro se destaca en el guión museográfico. Las múltiples interpretaciones del pasado se funden dentro del hilo conductor del dolor de las víctimas y de los habitantes de la ciudad (Lavielle, 2015). En efecto, la estructura de la exposición permanente se asemeja a lo que Philippe Mesnard llama una "configuración emocional" que privilegia 
la emoción en detrimento de la razón y que hace énfasis en la experiencia de las víctimas:

[...] no es que el historiador esté ausente sino que la autoridad de su discurso se eclipsa detrás de un relato individualizado, generalmente polifónico, hecho por enunciadores que hacen parte de una constelación familiar cuyo destino es contado [...] El lugar está impregnado por una intimidad que demuestra que se trata de vivencias reales (2012, p. 39).

Finalmente, para entender el mensaje de la sala de exposición permanente, es importante abordar el tema de la(s) responsabilidad(es). El equipo del MCM hizo un esfuerzo considerable para hablar de este tema, pues el museo se diferencia de la mayoría de los museos de la memoria y memoriales que eluden a este. Por ejemplo, al contrario del Museo de la Memoria y de los Derechos Humanos de Chile, el cual analiza la dictadura como un evento aislado en la historia y no menciona los responsables de los asesinatos o las militancias de las víctimas (Bastías Sekulovic, 2016), en el MCM, las responsabilidades del Estado colombiano, de los paramilitares, de las guerrillas y de los narcotraficantes están expuestas a través de los diferentes dispositivos. Sin embargo, estas responsabilidades son también plurales y emergen laboriosamente y al final, de manera somera, dentro de una cantidad considerable de informaciones y de capas de lectura. Los hechos se relatan a través de recursos simbólicos y de escasas cifras: el por qué o el contexto no es evocado y parecen estar desvinculados de dinámicas políticas que siguen pasando hoy en día. Si bien las responsabilidades políticas son plurales y se abordan de manera rápida, la responsabilidad del visitante está presente de manera latente durante toda la visita. El texto que introduce la sala lo dice: "al final, usted también hace parte de esta historia". Como lo explicó la coordinadora del equipo de museología, el museo tiene como propósito preguntar al visitante: "Y tú, como ciudadano, como visitante, ¿cuál es tu papel aquí y que puedes hacer?”. Además, el responsabilizar al visitante se fortalece a través de la museología del enfoque. Según esta museología, el visitante es activo porque su recorrido es libre, pues no hay que seguir un orden para deambular dentro de la exposición. Como Sharon Macdonald lo explica, el visitante se 
vuelve "consumidor que se involucra activamente dentro de un proceso de selección" (1993, p. 20). Al final, son los visitantes los que son responsables de la paz, dándose cuenta de las consecuencias del pasado violento de su ciudad y de su país. Sin embargo, detrás de la libertad dada al visitante y de la polifonía de los relatos resaltada por el museo, vamos a ver que hay una limitación y una prescripción de las emociones y de las percepciones que los visitantes pueden y deben sentir.

\section{Un visitante conmovido y al que se responsabiliza}

El MCM tiene una misión de formación de ciudadanos y de transmisión de valores, pues su misión es "la transformación de las lógicas de la guerra hacia prácticas más civilizadas" (Museo Casa de la Memoria, [en línea]). Existe un deber moral que influencia lo que se puede decir al salir de un lugar que habla de violencia y del dolor de las víctimas (Brown, 2014): la "configuración emocional" del relato encuadra lo que se puede sentir y decir al salir de la sala de exposición permanente. Las respuestas que dieron los visitantes a nuestras preguntas deben entenderse dentro de este marco. Además, el cuestionario que los visitantes llenaron durante nuestra investigación los obligaron a tener una mirada reflexiva sobre su propia experiencia de visita, lo que no es natural. La forma escrita del cuestionario lo hace parecer una tarea escolar que puede dar la impresión que tiene que contestarse de "manera correcta". Los siguientes resultados deben entonces entenderse como una primera aproximación hacia las percepciones y los sentimientos evocados por los visitantes del MCM a través de un dispositivo de investigación que los condiciona.

\section{El museo como fuente de historia y de emociones}

Ante todo, los visitantes encuestados ven el museo como un lugar de conocimiento. Más de la mitad califica su visita de "educativa" (69\%) y califica el Museo de "espacio histórico" (77\%) y "cultural" (69\%). Muchos visitantes dicen sentirse satisfechos, y a veces sorprendidos, al ver la historia colombiana "real" expuesta. En este sentido, usan dos 
criterios para medir la veracidad de lo que está expuesto. El primero es la neutralidad y la objetividad de la exposición, que es reconocida principalmente por los visitantes que se definen de izquierda o de extrema izquierda. Por ejemplo, un estudiante de 21 años, vecino del Museo, explica que la visita lo sorprendió: "El Museo es objetivo. No me vendieron la paz. En algunos pasajes dicen que el gobierno fue responsable. Eso sí me gustó. Es realista. No solo se habla de la guerra de Pablo Escobar" (Entrevista del 25 de abril de 2015)

El segundo criterio es la experiencia personal: el Museo cuenta la verdad porque habla de temas vividos de cerca o de lejos por los visitantes. El 73\% de los visitantes encuestados afirma tener un vínculo con las temáticas evocadas en el Museo, mientras que un 20\% dice tener un vínculo directo con el conflicto armado. Muchos visitantes piensan que sus compatriotas no estarían interesados en visitar el Museo justamente porque habla de temáticas que cada colombiano vive en su cotidianidad. Dentro de las cuarenta y dos personas entrevistadas, solo una mujer afirma no estar interesada por la historia del conflicto armado. Al ser enfermera, ha trabajado en varios pueblos antioqueños muy afectados por el conflicto armado. Señala sentirse "débil" y no tener la "fuerza espiritual para dedicar tanto tiempo a este tipo de cosas” (entrevista del 23 de abril de 2015). Además, justifica su falta de interés por su sensibilidad, lo que es distinto a una actitud indiferente. En efecto, la visita al MCM tiene una carga moral: confrontarse a la realidad y pasar su tiempo libre visitando una exposición que habla de una violencia que los visitantes vivieron o viven es un acto moral y un compromiso hacia la paz. De esta manera, ir al Museo es un deber, y "ver esta exposición es ante todo el deber de ver” (Gensburger, 2015, p. 92).

Como lo muestra el extracto de la entrevista con la visitante enfermera, la emoción es un registro a través del cual los visitantes hablan de su visita. Muchas personas compartieron sus sentimientos de tristeza, de impotencia y de abatimiento al salir de la sala de exposición permanente. En los cuestionarios, a la pregunta "¿Cuál es la sensación que tiene después de haber hecho la visita?”, un $55 \%$ de las ochenta y siete personas que contestaron dijo "tristeza". La omnipresencia 
del sentimiento de tristeza nos da pie para elaborar la hipótesis sobre una prescripción de emociones en el museo. Esta elaboración se basa en el trabajo del sociólogo Marcel Mauss quién, refiriéndose a los ritos funerarios australianos, habla de una "expresión obligatoria de los sentimientos" (1921, p. 425). En efecto, el autor explica que, dentro de la tribu australiana que estudia, se espera de las mujeres expresen su tristeza a través de ciertos gritos y cantos. Mauss señala que la expresión obligatoria de los sentimientos no significa que las mujeres no sean sinceras cuando gritan y lloran, pero que su rol dentro del grupo es expresar su dolor de una manera precisa. Aplicando esta idea al MCM, podemos decir que se espera de los visitantes que expresen su tristeza al salir del Museo, porque toda la exposición está enfocada hacia el dolor de las víctimas. Otro elemento que explica la expresión de tristeza es el cruce entre la historia y la relación personal de los visitantes con esta. Una vecina del MCM, artista plástica cuyo hermano desapareció, nos dice que el Museo "le hizo acordarse de sus propios muertos" (entrevista del 18 de abril de 2015). Otro visitante, un ingeniero de 48 años que vive en un barrio de clase media y que estaba con su esposa y con su hija de 18 años cuenta:

Viví esta violencia en Medellín, de la época del narcotráfico, de Pablo Escobar, del narcotráfico, cuando era niño, era joven. Y lo que acabo de ver me impresionó demasiado porque volver a recordar, a rememorar la historia de un Medellín que padeció esta violencia de manera tan impresionante. Pero digamos que nuestra hija que nació en el 97 no le tocó, estaba apenas cambiando. Pero esto es horrible. O sea, es volver a recordar cada homicidio, cada secuestro, cada bomba del narcotráfico. Es como mostrar la cara triste de un Medellín pasado. Entonces es difícil. Salgo bastante impactado (entrevista del 25 de abril de 2015).

Este visitante tiene una posición de testigo de la violencia de los años ochenta. La exposición lo hace pensar en su propia vivencia como adolescente y son estos recuerdos los que provocan en él el sentimiento de tristeza e incluso de horror. Asume también un segundo rol, el de padre. Apenas la entrevista había empezado, comienza a hablar su hija. Ella estudia en un colegio privado en el barrio de clase alta, El Poblado, 
donde se organizan actividades con la ONU y que tienen, según él, el objetivo de "concientizar a los jóvenes, decirles que hay un Medellín pasado, un Medellín presente y un Medellín futuro" (entrevista del 25 de abril de 2015). Como padre, delega en su hija el futuro pacífico y exitoso de su ciudad. Dependiendo del rol que asume, la relación de este visitante con la exposición cambia: la tristeza que sintió como testigo de la violencia se mezcla con la creencia en el futuro cambio de su ciudad, en el cual su hija tendrá un rol importante. Nuestro estudio muestra, en efecto, que una representación recurrente evocada por los visitantes, sea cual sea su clase social, su género o su edad, es que la superación del conflicto armado debe ocurrir con la movilización individual de cada colombiano.

\section{El sentimiento de responsabilidad individual}

Algunas tendencias se destacan cuando se pregunta a los visitantes cuál es el mensaje que, según ellos, el MCM trata de transmitir. Con frecuencia, hablan de la responsabilidad de cada colombiano dentro de la existencia y de la persistencia de un conflicto armado. Es una lección sobre su comportamiento individual, como ciudadano, la que la mayoría de los visitantes extrae de su recorrido por el MCM. Esta actitud difiere de lo que se ha observado en Bélgica con el público joven de una exposición que trataba de las víctimas de la Primera Guerra Mundial. En efecto, los investigadores mostraron que sus actitudes pacifistas bajaban después de la visita (Bouchat, Klein \& Rosoux, 2016). Observamos lo contrario en Medellín: los visitantes del MCM se sienten responsables de la violencia pasada y de la paz futura. A este respecto, podemos señalar la hipótesis de que la distancia temporal con la Primera Guerra Mundial en Europa aleja los visitantes del discurso expuesto en los museos, mientras que la cercanía de los visitantes colombianos con los hechos relatados en el MCM favorece un sentimiento de responsabilidad frente a las consecuencias del conflicto armado allí expuestas, y un incremento de la sensación de empatía hacia el dolor de las víctimas. 


\section{6 / Julie Lavielle}

El registro de responsabilización individual se comparte por todos los visitantes, sea cual sea su clase social, su edad o su orientación política. En efecto, esta última no tiene ningún impacto sobre este sentimiento de responsabilidad. El padre que acabamos de mencionar, y que se define de derecha, afirma que "en realidad, todos somos actores del conflicto. Si usted se queda en su casa, escondido, es un actor del conflicto porque no es capaz de salir a ayudar o a convencer a la gente" (entrevista del 25 de abril de 2015). Según un estudiante anarquista de 21 años, "todos somos responsables de la guerra, él que compra un fusil para matar a alguien por una ideología o por dinero igual que él que se queda en el silencio detrás de su televisión" (entrevista del 24 de abril de 2015). La idea de que cada colombiano es individualmente responsable se imbrica dentro de una creencia en la capacidad del museo de transformar los espíritus que estuvieron indiferentes frente a la violencia. Muchos visitantes evocaron la necesidad de "concientizarse" y de ser más "humanistas". La visita al MCM se ve como un medio para cumplir esta necesidad. La gran mayoría de los visitantes dijeron que, en efecto, "hacer memoria" era un paso necesario para avanzar hacia la paz. Escuchar el testimonio de las víctimas es una prueba de la apertura de los visitantes y de su tolerancia.

Así, "humanismo", "tolerancia", "reflexión” y "concientización" son los valores y las prácticas que los visitantes evocan al salir del MCM. Los visitantes salen del museo sintiéndose responsables de la violencia que ocurrió en Colombia y en Medellín y responsables de la construcción de la paz. El registro de la responsabilización incita cada individuo a volverse agente de cambio: no son las instituciones o las modalidades de distribución del poder y de las riquezas que deben cambiar, sino los ciudadanos. Este registro contribuye a la "desvalorización de los asuntos de 'interés general' y más generalmente al rechazo de lo político y a la reducción de la vida en sociedad hacia preguntas sobre la eficacidad, la seguridad y la moralidad" (2012, p. 126), como lo demostró Isabelle Hibou en su estudio del neoliberalismo. En este sentido, los visitantes entrevistados evocan las ideas desarrolladas en el MCM: los valores de tolerancia, de humanismo y de apertura al diálogo son las claves para construir la paz, y cada colombiano tiene que apropiárselas. Sin embargo, el propósito de este artículo no es poner en evidencia una recepción pasiva de un mensaje 
unívoco. En lugar de concluir que los visitantes han incorporado un mensaje, preferimos deducir de nuestro análisis que los visitantes se ajustan a lo que se espera de ellos en un museo que relata el conflicto armado colombiano.

Durante este primer análisis de las entrevistas hechas con los visitantes, varios relatos biográficos emergieron. En efecto, los visitantes del MCM perciben su contenido a través de muchos filtros, como su trayectoria biográfica (¿vivieron los acontecimientos narrados en la exposición?, ¿con qué distancia?), los diferentes roles que asumen durante su visita (testigo, padre) o sus convicciones políticas (estar satisfecho frente a un discurso calificado de "objetivo"). Hace mucho tiempo que la sociología muestra que el individuo no es una hoja en blanco en la que cualquier institución o actor puede inscribir algunas representaciones, algunos valores o algunas opiniones políticas (Lazarsfeld Berelson \& Gaudet, 1969). Enseguida nos enfocaremos en el papel que tienen las convicciones políticas y la trayectoria biográfica de los visitantes sobre su percepción y su apropiación de los relatos expuestos en el MCM.

\section{Los filtros de percepción de la exposición}

Esta investigación se orientó bajo el principio de que la transmisión de la historia dentro del Museo se hace a través de un proceso de apropiación y no solamente de transferencia. La historia se interpreta de manera diferente por cada visitante: la transmisión funciona cuando hay un vínculo entre la experiencia personal del visitante, sus opiniones y valores, $y$ el contenido expuesto en el museo. En esta sección vamos a explorar dos filtros a través de los cuales los visitantes se apropian de la historia narrada en el museo: sus opiniones políticas y su experiencia personal en el marco del conflicto armado. 


\section{Política y apolitismo en el museo}

El posicionamiento político de los visitantes que participaron en la encuesta es original: el $60 \%$ se ubica a la izquierda del escenario político, el 9\% al centro, el 3\% a la derecha, mientras el $27 \%$ no contestó. Las afinidades políticas de los visitantes de la muestra son sensiblemente más de izquierda si las comparamos con las afinidades de la población colombiana en general, que se divide en tres bloques casi iguales: el 30,7\% se ubica a la izquierda, el 39,5\% al centro y el 29,4\% a la derecha (Galindo, 2018). La mayoría de los visitantes dicen considerar el Museo y su visita como apolíticos, el $77 \%$ de los visitantes no califica el museo de político y solo el $27 \%$ califica su visita de política. Sin embargo, apolítico no significa des-politizado. Observamos, en efecto, una correlación entre el posicionamiento ideológico a la izquierda y la calificación de la visita de "política".

Tabla 1. Posicionamiento ideológico de los visitantes y calificación de la visita

\begin{tabular}{|l|c|c|c|c|c|c|c|c|}
\hline $\begin{array}{c}\text { ¿Calificaría su } \\
\text { experiencia } \\
\text { de visita de } \\
\text { política? }\end{array}$ & \multicolumn{2}{|c|}{ No } & \multicolumn{2}{c|}{ Sín } & \multicolumn{2}{c|}{ Sin respuesta } & \multicolumn{2}{c|}{ Total } \\
\hline $\begin{array}{l}\text { Posicionamiento } \\
\text { Izquierda/ } \\
\text { Derecha }\end{array}$ & $\begin{array}{c}\text { Nro. } \\
\text { de } \\
\text { visi- } \\
\text { tantes }\end{array}$ & $\begin{array}{c}\% \text { de } \\
\text { visi- } \\
\text { tantes }\end{array}$ & $\begin{array}{c}\text { Nro. } \\
\text { de } \\
\text { visi- } \\
\text { tantes }\end{array}$ & $\begin{array}{c}\% \text { de } \\
\text { visi- } \\
\text { tantes }\end{array}$ & $\begin{array}{c}\text { Nro. } \\
\text { de } \\
\text { visi- } \\
\text { tantes }\end{array}$ & $\begin{array}{c}\% \text { de } \\
\text { visi- } \\
\text { tantes }\end{array}$ & $\begin{array}{c}\text { Nro. } \\
\text { de } \\
\text { visi- } \\
\text { tantes }\end{array}$ & $\begin{array}{c}\% \text { de } \\
\text { visi- } \\
\text { tantes }\end{array}$ \\
\hline Centro & 11 & $92 \%$ & 1 & $8 \%$ & 0 & $0 \%$ & 12 & $100 \%$ \\
\hline Derecha & 0 & $0 \%$ & 0 & $0 \%$ & 7 & $100 \%$ & 7 & $100 \%$ \\
\hline Izquierda & 90 & $80 \%$ & 20 & $20 \%$ & 0 & $0 \%$ & 112 & $100 \%$ \\
\hline Total & 101 & $77 \%$ & 23 & $18 \%$ & 7 & $5 \%$ & 131 & $100 \%$ \\
\hline
\end{tabular}

Fuente: Elaboración propia.

El cuadro más arriba muestra que la gran mayoría de los visitantes no califica su visita de política $(77 \%)$, pero que los visitantes que se ubican a la izquierda son los más numerosos al calificar su visita de política. Las entrevistas con los visitantes permiten entender más precisamente la influencia que puede tener la sensibilidad política de izquierda sobre las percepciones del discurso divulgado por el Museo. 
Cuando los visitantes se refieren a los personajes famosos que vieron en la exposición, vemos que su opinión política tiene un papel importante en su percepción de la visita y del MCM. Durante una entrevista con dos amigos que se ubican a la extrema izquierda, el primero, estudiante y vecino del Museo, afirma que "Colombia es el dolor de las madres, la política, el liderazgo, la opresión de la libertad. Me siento incomprendido. Muchas veces porque soy diferente. Es lo que pasó a Galán, a Garzón” (entrevista de 25 de abril de 2015). También menciona a "la mujer que contaba la historia de su hijo desaparecido", haciendo referencia a Fabiola Lalinde, cuyo hijo, militante comunista fue desaparecido por el Ejército en 1984. El amigo de este visitante, profesor en un colegio, insiste sobre la figura de Gloria Cuartas, lideresa de la izquierda colombiana cuyo testimonio se difunde en una pantalla de la sala: "Me dije: 'Gloria Cuartas. Hay que escuchar a Gloria Cuartas. Para que cuente su experiencia de resistencia"' (entrevista de 25 de abril de 2015). Estas personalidades políticas hacen parte de la izquierda colombiana, igual que estos dos visitantes. El relato de Fabiola Lalinde marca también a una joven pareja de estudiantes de 20 años. Cuando les preguntamos si se acordaban de un testimonio o de una historia en particular, la mujer contesta muy rápidamente: “ ¡el testimonio de la mujer!" (entrevista de 25 de abril de 2015). Su pareja, quien se define como anarquista, agrega: "desaparecieron a su hijo. Porque era militante de un partido político" (entrevista de 25 de abril de 2015). Sus recuerdos tienen un lazo con sus identidades de estudiante anarquista para él, y de estudiante feminista para ella. Mientras él se acuerda de Iván Cepeda y del testimonio de un profesor que habla de la creación de un sindicato, ella se acuerda de la mesa temática que habla de los indígenas ("nadie sabe de ellos" (entrevista de 25 de abril de 2015) y de la mesa que habla de las mujeres: "la mesa que dice 'nos maltrataron, nos violaron, pero sobrevivimos'. ¡Aquí hay mucho machismo! ¡Es importante seguir en la lucha!” (entrevista de 25 de abril de 2015). Aquí vemos que las convicciones políticas guían, enmarcan y modelan lo que los visitantes perciben de la visita.

Finalmente, dentro de las personas entrevistadas y encuestadas, solo un visitante formuló una crítica muy fuerte del Museo. Se trata de un colombiano de 35 años que nació en el Urabá y que se exilió en Argentina. Militante político, fue amenazado y tuvo que salir del país. Cuando sale 
de la sala de exposición con su hijo de 4 años de la mano, estaba muy conmovido. Nos explica que huyó de Colombia porque ya no aguantaba la intolerancia de sus compatriotas. Comparando su país de origen con su país de refugio, critica la complicidad de los colombianos que legitiman los asesinatos y las desapariciones diciendo que "algo habrá hecho". Formula además una crítica sobre la "revisión de la historia" hecha por el MCM, pues según él falta mucha información en cuanto a los acontecimientos históricos internacionales presentados en la cronología. También es el único visitante que habla del contexto de construcción del MCM, que ocurrió después de la destrucción de un barrio popular llamado La Toma: “¿Preguntaron a la gente del barrio si querían este lugar? Construimos parques, bibliotecas para que Medellín parezca bonita. Pero aquí no hablamos de los insurgentes. Hay que nombrar todo el mundo, hay que castigarlos" (entrevista de 25 de abril de 2015). Finalmente, es el único visitante que se refiere a la necesidad de castigar a los responsables del conflicto armado. En este sentido, podemos formular la hipótesis de que un pasado de militante político amenazado y su emigración a Argentina, país en el que algunos miembros de la dictadura de 1976-1983 fueron juzgados, orientan el análisis que hace de la exposición. De este modo, la visita de la exposición reactualiza su posición crítica hacia el Gobierno colombiano y la relación de este con los oponentes políticos. El análisis del cruce entre la experiencia biográfica de los visitantes y el relato del conflicto armado propuesto por el MCM es entonces una pista de reflexión interesante.

\section{Recuerdos familiares}

La reflexión de Maurice Halbwachs sobre el cruce entre los recuerdos individuales y la historia nacional es heurística para analizar la apropiación de la narración propuesta por el MCM. Según Halbwachs, "nuestra memoria no se apoya sobre la historia aprendida sino sobre la historia vivida" (1997, p. 105). Si una persona puede situar sus propios recuerdos dentro de una pintura que representa la historia contemporánea, es porque su pasado ya tenía la huella de la historia contemporánea. Los visitantes del museo vivieron y viven la historia que está contada en el museo. La reflexión de Halbwachs es muy pertinente para estudiar 
el caso de Medellín, porque es muy frecuente que los recuerdos personales de los visitantes crucen la historia municipal, regional o nacional narrada en el MCM. Los visitantes del MCM perciben la historia que ven plasmada en las pantallas cronológicas, por ejemplo, a través de sus recuerdos biográficos y familiares. No es que calquen artificialmente sus recuerdos sobre el relato del Museo, sino que reconocen en este relato las huellas históricas que impregnan sus recuerdos personales. Es entonces interesante ver que "aunque los dispositivos de evocación publica del pasado son pensados para provocar la emergencia de una memoria histórica común ligada [al conflicto armado colombiano], provocan ante todo la expresión de recuerdos biográficos y familiares" (Antichan \& Teboul, 2016, p. 37). Muchos visitantes evocan sus recuerdos personales y familiares durante las entrevistas. El ejemplo de dos visitantes, madre e hija de 82 y 65 años, ilustra esta idea de forma particular. Durante su visita, se detienen delante de una fotografía de la iglesia de Bojayá, destruida por una bomba e intercambian:

-Hija: ¿Viviste esta época? ¿La Violencia?

-Madre: Sí. Los conservadores, eran ellos los que mataban

(Observaciones, 26 de abril de 2015).

Si bien la fotografía de la iglesia de Bojayá destruida aludía a la bomba lanzada por las FARC-EP en 2002, ella sirve de soporte para evocar los recuerdos de un periodo histórico diferente, el de la Violencia. No es el contenido de la fotografía lo que importa sino el contexto de la exposición, el propicio para evocar los recuerdos:

—Julie Lavielle (J. L.): Si contaran lo que acaban de ver a un amigo o a un familiar, ¿qué contarían?

—Madre: Esto es muy bonito, muy elegante.

- Hija: ¿Qué contaría a las amigas de la gimnasia?

-Madre: Que vinieran para ver la guerra de los cuarenta. Yo estuve en el 48, en la guerra de los 48. Allí fue donde empezó.

—Hija: Lo que llaman qué... ¿la guerra de las bananeras?, ¿o la de los mil días?

—Madre: No, la guerra del 9 de abril.

-Hija: Es lo que usted quería ver. 
-J. L.: Hay un problema técnico hoy y la pantalla con la cronología no funciona... ¿Usted vivió la Violencia en Medellín o estaba en un pueblo?

-Madre: No, estaba en una finca. En Nariño, Antioquia. Había muchos muertos. En una parte que se llama Puente Linda. Eso allá era horrible. Era horrible, horrible, horrible. Y eso se oía desde la casa, los tiroteos, se peleaban...

-Hija: Pero los conservadores...

—Madre: Era los conservadores contra los liberales, ¿cierto que sí? -J. L.: Sí.

-Madre: Los conservadores mataban los liberales, entonces los liberales tenían que volarse.

-J. L.: ¿Y en su familia, eran liberales?

-Madre: En una parte eran liberales y en otra parte eran conservadores. Y un día los liberales se volaron, pasaron por el río por allá por otra parte. $[\ldots]$

-J. L.: ¿ A partir de cuándo fue más tranquilo?

-Madre: Eso no duró mucho tiempo, duró como un mes. Esa violencia.

-Hija: Entonces usted quería ver eso.

-J. L.: ¿Por qué quería ver?

—Madre: ¡Pues a ver cómo iba a ser! (ambas se ríen)

—Hija: ¡Ah! ¡Porque usted no salía!

—Madre: iNo, que me iba a salir Dios mío! No...

- Hija: Entonces a usted no le pasó nada.

-Madre: No pues eso era miedoso. (entrevista del 26 de abril de 2015).

Su visita es una ocasión para evocar recuerdos de infancia y de juventud, para la madre, y la "historia aprendida" (Halbwachs, 1997, p. 105) para la hija, que no parece estar acostumbrada a visitar museos y que intenta responder "correctamente" a nuestras preguntas, multiplicando las referencias históricas (Masacre de las bananeras, Guerra de los Mil Días). La hija se apoya sobre los recuerdos de su madre para apropiarse de un periodo histórico que no conoció. Finalmente, la madre afirma "querer ver" algo dentro de la exposición — la Violencia — y 
aunque no encuentra lo que buscaba, la visita con su hija creó una situación propicia para evocar sus propios recuerdos de la Violencia.

En los párrafos anteriores, intentamos mostrar que, aunque en el museo hay un "discurso social estándar" que se despliega y que transmite un sentimiento de responsabilización individual a los visitantes, estos últimos se apropian del contenido expuesto a partir de su propia experiencia del conflicto armado, y de acuerdo a sus afinidades políticas. Esta conclusión intermedia atenúa la idea de la capacidad transformadora de la memoria y de la transmisión del pasado violento, porque vemos que los visitantes encuentran en el Museo lo que estaban dispuestos a encontrar. A pesar de los valores y de las emociones que son prescriptos por el Museo, los visitantes interpretan el mensaje polifónico la exposición a través de sus propios valores y de sus propias percepciones del pasado.

\section{Recordar en el Museo y en tiempos de conflicto: La economia moral de los visitantes}

Teniendo en cuenta el resultado de un poder limitado del MCM en la transmisión de una memoria sobre el pasado violento, esta última parte analiza la relación de los visitantes del Museo con la violencia. ¿Qué influencia tiene una exposición que narra la violencia sobre la relación del público con su propia vivencia de la violencia? Esta última parte tiene como objetivo entender la "economía moral" de los visitantes frente a la violencia. Este concepto del sociólogo Didier Fassin designa "la producción, la repartición, la circulación y el uso de los sentimientos morales, de las emociones y de los valores, de las normas y de las obligaciones dentro del espacio social" (2009, p. 1257). En otras palabras, la economía moral es el conjunto de principios de evaluación que organizan la percepción de la violencia como legítima, infundada, justa o injusta. En esta parte mostramos que la economía moral de los visitantes se encuentra en la disyuntiva entre la condena de la violencia y el acostumbramiento a su uso. 
Las entrevistas hechas con los visitantes son un buen método para tratar de entender la originalidad de Colombia, un país en el que, mientras se desarrollan relatos públicos sobre el conflicto armado, este sigue vigente. Durante las veintidós entrevistas que hicimos, solamente dos personas hablaron de un vínculo directo con el conflicto armado porque eran víctimas. Sin embargo, era sorprendente ver cómo, a medida que las conversaciones se desarrollaban, se desprendía que la vida cotidiana de todos los visitantes colombianos ha sido penetrada por el conflicto armado, de alguna u otra manera. En este contexto, un resultado interesante de las entrevistas es que los visitantes diferencian la violencia evocada por el Museo (violencia que toca la sociedad colombiana en su conjunto y que, por medio del Museo, se vuelve una historia legítima y colectiva) y la violencia que toca sus vivencias personales. Se deduce de esto una posición paradójica: por un lado, el público sale triste y agobiado por la acumulación de dispositivos que hablan de la violencia que afectó a Colombia. Pero, por otro lado, el público relativiza e incluso justifica la violencia que ha conocido desde siempre y con la que convive diario. El intercambio entre dos estudiantes en pedagogía ilustra esta posición paradójica:

—Julie Lavielle (J. L.): ¿En sus familias hablan del conflicto armado?

—Estudiante 1: Tengo familia en una vereda cerca de Ituango. Nosotros vamos allá mucho. Allá los que mandan son la guerrilla. No lo dejan a uno tener un celular, no se puede tener computadores, no se puede tener cámaras. Es muy explícito lo que uno tiene que hacer. Y por las montañas, pobre Ejército, los campesinos no les pueden dar agua porque si no los matan. [...] Cuando uno quiere salir del pueblo, no puede salir después de las $6 \mathrm{p}$. m. porque le puede explotar una mina. [...] El pueblo se cierra.

-Estudiante 2: Y en los barrios se comenta mucho la seguridad. Porque en los barrios se cobra "la vacuna". En el transporte, en la gente que tiene su tienda, todo lo que se comercializa. Entonces, la gente está tratando de salir adelante pero cada ocho días recibe su vacuna. Incluso en casas. Se le cobra la seguridad. El celador. Pero nunca se ve. Tienen una cuota y dicen que es por la seguridad. Pero no sé... y debajo de mi casa hay un CAI. ¡Y no pasa nada! 
—Estudiante 1: Pero lo que digo de mi pueblo. [...] Hay la guerrilla. Pero se puede salir hasta las doce de la mañana, no hay muertos, no pasa nada. Por el simple hecho de que la guerrilla manda, hay límite de velocidad de motos, si uno no la cumple le cobran multa, como 100000 pesos. No se puede andar con machete. Y cuando fui allá hubo un sapo. Un infiltrado. Lo estaban buscando, súper horrible, para matarlo. Es horrible pero a la vez es bueno porque en un pueblo como ese. Porque no hay violencia adentro pero hay violencia afuera (entrevista del 18 de abril de 2015).

En 1997, Daniel Pécaut publica un artículo sobre la banalización de la violencia en Colombia. Según Pécaut, la población civil colombiana sitúa su propia vivencia dentro de una temporalidad de la violencia continua, que sigue siendo la misma desde los años cuarenta. El intercambio entre las dos estudiantes en pedagogía muestra cómo la violencia generalizada se integra dentro de la vida cotidiana de la población civil y cómo ella genera una manera de entender el mundo social (Pécaut, 1997). Más allá de una manera de ver el mundo, este intercambio nos muestra cómo la violencia puede ser aceptada cuando esta se ejerce con fines de control social y de orden. La estudiante que visita a su familia en una zona controlada por la guerrilla pone de relieve los límites del discurso del MCM que está enfocado en la paz: ella reconoce que el control ejercido por la guerrilla tiene algo "bueno" ("no hay violencia adentro"), aunque pueda generar una violencia extrema (el asesinato de un sapo) y la restricción de la libertad de los habitantes (toque de queda, cierre del acceso al pueblo, control de velocidad). Por su lado, su amiga expresa un escepticismo en cuanto a la eficacia de la policía, pues en su barrio los bandos extorsionan los habitantes al frente de una estación de policía. Al salir de la sala de exposición permanente, las interpretaciones sobre la violencia no son unívocas: la violencia puede ser aceptada e incluso justificada cuando sirve para un objetivo que se considera loable y justo, como lo es el orden y la tranquilidad. Se destaca así una frontera entre lo que los visitantes dicen a propósito de la exposición (y lo que se espera de ellos al salir de la exposición) y su percepción de la violencia que viven a diario. 


\section{6 / JULie LAVIELLe}

Durante esta conversación, las dos estudiantes evocaron la figura de Pablo Escobar. La imagen del narcotraficante es ambigua. El fundador del Cartel de Medellín es a la vez famoso por sus actos violentos y sus manifestaciones de solidaridad hacia los habitantes pobres de Medellín. En efecto, financió la construcción de un barrio al cual muchos habitantes del barrio de recicladores de Moravia se fueron a vivir después de un incendio. Durante la entrevista, las dos estudiantes de pedagogía evocaron a Pablo Escobar así:

-Estudiante 1: Pablo Escobar era malo. Fue el peor narcotraficante. Pero muchas personas lo lavan porque a pesar de lo malo, hizo cosas buenas para los pobres.

-Estudiante 2: Construyó un barrio, un hospital. Cosas muy buenas. Hizo cosas que ni siquiera el presidente hizo. Entonces mire que, de todas maneras, así haya hecho narcotráfico, tantas muertes y todo... también hizo cosas buenas. [...] Entonces uno tiene que ser muy realista y decirles a los niños la verdad. Un personaje que hizo cosas buenas pero que no es digno imitar. Mire como terminó, muerto por allá en un techo (entrevista del 18 de abril de 2015).

Defender la no-violencia, la convivencia y la honestidad por un lado no impide valorizar la figura de Pablo Escobar, por el otro, pues es un personaje "importante" que hizo "cosas buenas". Esta posición, aparentemente contradictoria, no significa que estas dos visitantes se olvidaron o no entendieron los mensajes de la exposición permanente. Es cierto que los diferentes dispositivos de la sala explican las consecuencias del conflicto armado, en el cual el narcotráfico tuvo un papel importante: desapariciones, asesinatos, atentados, represión de movimientos políticos... Sin embargo, estos hechos se equilibran con las "cosas buenas" que hizo Pablo Escobar. Finalmente, la conversación de las estudiantes concluye con la mención de valores como la honestidad, la dignidad y la no violencia y no contradicen el mensaje de la sala de exposición permanente. Pablo Escobar puede ser asociado a estos valores positivos, pues construyó un barrio, hizo cosas que "ni siquiera el presidente hizo" (entrevista del 18 de abril de 2015), y colaboró en el desarrollo de la ciudad. 
Las ideas aquí expuestas ameritan un trabajo de campo más en detalle para profundizar el análisis sobre la economía moral de los colombianos frente a la violencia. Sin embargo, nos parecen importantes plantearlas en un contexto en el que se habla de posconflicto, pues ¿de qué tipo de paz hablamos si un cierto grado de violencia, dirigido hacia un determinado tipo de personas, y que sirve par ciertos objetivos considerados legitimos sigue siendo justificado? El conflicto armado colombiano y sus modalidades explican la relación particular que se establece con la violencia, así como la existencia de una frontera entre un discurso sobre la importancia de hacer memoria para construir la paz, y la percepción que los visitantes tienen de la violencia que conocen diariamente. Además, el discurso de la sala de exposición permanente del museo es otro factor explicativo de esta dicotomía. La pluralidad de los tipos de víctimas, de los tipos de violencias y de la diversidad de los puntos de vista sobre el conflicto armado no desembocan en una lectura clara del conflicto armado frente a la cuál los visitantes puedan tener una opinión, ya sea a favor o en contra. La confusión que resulta de ello (cada uno puede ver lo que quiere ver) fortalece el consenso alrededor de la importancia de recordar (aunque no se sabe qué) y de rendir homenaje a las víctimas (aunque no se sabe claramente de quién). La socióloga Alexandra Oeser observa un fenómeno parecido en su estudio sobre la enseñanza del nazismo en las escuelas alemanas: 'la fórmula 'recordar' no tiene ningún atributo: ¿recordar qué? [...] Esta falta de contenido permite un consenso muy amplio sobre un imperativo categórico: cada uno puede interpretar el deber de memoria como quiere" (2010, p. 360). El contenido de la exposición entonces, por un lado, deja un espectro de interpretación muy largo y, por otro lado, invita a cada visitante a centrar su interpretación alrededor de ciertos valores que parecen determinantes para la salida del conflicto (humanismo, tolerancia).

De esta manera, el "discurso social estándar" difundido en el Museo, y que se enfoca en la responsabilidad colectiva de los colombianos, a la vez que subraya la importancia de valores como la "tolerancia", el "bien" y la "paz", esconde una economía moral de la violencia más ambigua. Detrás del consenso visible sobre "todos los colombianos 
son responsables", vemos que el tema de la condena de los actos violentos no es totalmente compartido.

\section{Conclusión}

El análisis que hemos propuesto a lo largo de este artículo expone varios mecanismos para entender los límites del "soplo transformador de la memoria". Primero, los visitantes del Museo Casa de la Memoria (MCM) vienen al museo para "encontrar" representaciones del pasado que dependen de varios factores que se encuentran más allá del Museo y que son preexistentes: sus opiniones políticas, los momentos del conflicto armado que han vivido, la fuerza con la que el conflicto armado cruzó su trayectoria biográfica, las referencias culturales y las personalidades presentes en la sociedad colombiana y los diferentes roles que asumen durante su visita. De esta manera, la visita al MCM no altera necesariamente las representaciones sobre el conflicto armado que tienen los visitantes, porque perciben un relato que estaban dispuestos a percibir.

Segundo, la museología del enfoque, que deja el visitante libre en su recorrido, y la pluralidad de lecturas propuestas por la exposición terminan dejando al visitante solo frente a su culpa. La visita tiende a fortalecer la idea según la cual cada colombiano posee una parte de la responsabilidad colectiva de la existencia del conflicto armado, siendo también responsable de su resolución. La consecuencia de esta idea es que ella no cuestiona la historicidad del conflicto armado o de sus eventuales raíces socio-económicas, no cuestiona tampoco el ejercicio de la violencia como medio de regulación del orden y de las relaciones políticas y sociales. En este sentido, la visita se percibe como un acto cívico que es una prueba del compromiso de los visitantes con la construcción de un país pacificado y no desemboca en una reflexión sobre los mecanismos que explican la duración y la persistencia del conflicto armado colombiano. El discurso (político) que emerge entre los visitantes tiende a despolitizar las dinámicas del conflicto armado (la única excepción fue el caso de un colombiano exiliado). 
Finalmente, hemos tratado de mostrar que, si bien los visitantes se reconocen dentro del relato del MCM, no reconstruyen su propia vivencia actual de la violencia. En efecto, existe una frontera entre lo que los visitantes dicen sobre la exposición y sobre el pasado violento que allí se relata y lo que dicen sobre la violencia actual que se vive diariamente. De esta manera, la economía moral de los visitantes es amplia y variable porque tienen una relación cambiante con la violencia y juzgan su uso de más o menos legítimo según el periodo en el que se ejerce y los principios que la orientan. Dicho de otro modo, la economía moral que los visitantes emplean en el MCM difiere de la economía moral que guía su juicio sobre la violencia que observan o que viven diariamente. Convocan un registro de valoración y análisis diferente cuando evocan el conflicto armado que sigue existiendo en su vida cotidiana de manera más o menos cercana (la violencia que ejerce la guerrilla en un pueblo se acepta cuando mantiene el orden "apaciguado", o se acepta como un elemento inmutable de la vida cotidiana), de cuando hablan del relato del conflicto armado desplegado en el Museo (en este caso, condenan la violencia).

De envergadura modesta, este estudio debe apreciarse como una versión indagatoria de una investigación más amplia sobre la relación que tiene la población civil, que no se moviliza alrededor de la memoria, con el pasado violento de Colombia y con la violencia que se vive diariamente. Es una invitación a ir más allá de la constatación de una apatía o de un desinterés de los colombianos hacia el reto de la construcción de una memoria histórica del conflicto armado. En efecto, la economía moral de los visitantes muestra que no son indiferentes frente a la violencia, sino que se encuentran atrapados entre las contradicciones de un país en el que, mientras se desarrolla una política de pacificación y de reconocimiento de las víctimas, la violencia sigue siendo cotidiana y muchas veces legítima.

\section{Referencias}

Antichan, S., \& Teboul, J. (2016). Faire l'expérience de l'histoire ? Retour sur les appropriations sociales des expositions du centenaire de la 
Première Guerre Mondiale. Matériaux pour l'bistoire de notre temps, 3-4(121-122), 32-39.

Bastías Sekulovic, M. (2016). Del relato oficial a la recepción de los visitantes: análisis de la puesta en escena del pasado reciente en el Museo de la Memoria y de los Derechos Humanos de Chile”. En I. Arrieta Urtizberea (Ed.), Lugares de memoria traumática: representaciones museográficas de conflictos políticos y armados (pp. 199-219). Bilbao: Universidad del País Vasco

Bouchat, P., Klein, O., \& Rosoux, V. (2016). L'impact paradoxal des commémorations de la Grande Guerre. Matériaux pour l'bistoire de notre temps, 3-4(121-122), 26-31.

Brown, J. A. (2014). "Our National Feeling is a Broken One": Civic Emotion and the Holocaust in German Citizenship Education". Qualitative Sociology, 37(4), 425-442. https:/ / doi.org/10.1007/s11133-014-9286-8

David, L. 2017. "Against Standardization of Memory”. Human Rights Quarterly, 39(2), 296-318. https://doi.org/10.1353/hrq.2017.0019

Delacroix, D. (2014). "Somos peruanos y limpios". Discursos y prácticas en torno al monumento "El ojo que Llora" de Llinque, Apurímac. En Bulletin de L'Institut Français d'Études Andines, 43(2), 227-244. https:/ / doi.org/10.4000/bifea.5203

Fassin, D. (2009). Les économies morales revisitées. Annales. Histoire, Sciences Sociales, 64 (6), 1237-1266. https://doi.org/10.3917/anna.646.1237

Fassin, D., \& Rechtman, R. (2007). L'Empire du traumatisme. Enquête sur la condition de victime. París: Éditions Flammarion.

Feldman, J. (2010). Above the Death Pits, Beneath the Flag: Youth Voyages to Poland and the Performance of Israeli National Identity. Nueva York: Berghahn Books.

Galindo, J. (2018). ¿Es Colombia un país de derecha? Quizás lo está dejando de ser. El País. Recuperado de https://elpais.com/internacional/2018/02/25/colombia/1519592213_064747.html

Gensburger, S. (2015), Voir et devoir voir le passé. Retour sur une exposition historique à visée commémorative. Critique Internationale, 68(3), 81-99. https://doi.org/10.3917/ crii.068.0081

Gensburger, S., \& Lefranc, S. (2017). À quoi servent les politiques de mémoire? París: Presses de Sciences Po. 
Guglielmucci, A., \& López, L. (2019). Restituir lo político: los lugares de memoria en Argentina, Chile y Colombia. En Kamchatka. Revista de análisis cultural, (13), 31-57. https://doi.org/10.7203/KAM.13.12409 Halbwachs, M. (1997). La mémoire collective. París: Albin Michel.

Hibou, B. (2012). La bureaucratisation du monde à l'ère néolibérale. París: La Découverte.

Jaramillo Marín, J. (2010). La reconstrucción de la memoria histórica del conflicto colombiano en el actual proceso de Justicia y Paz. Alcances, desafíos y preguntas. En Desafíos, 22(2), 31-70.

Jelin, E., \& Langland, V. (2003). Monumentos, memoriales y marcas territoriales. Madrid: Siglo Veintiuno Editores.

Lazarsfeld, P., Berelson, B., \& Gaudet, H. (1969). The People's Choice: How the Voter Makes Up His Mind in a Presidential Campaign. Nueva York: Columbia University Press.

Lavielle, J. (2015). «Revendiquer nos victimes est la condition première pour avancer sur le chemin de la réconciliation»: construire la paix à travers une politique publique de la mémoire à Medellín (Colombie). Nuevo Mundo, Mundos Nuevos. https://doi.org/10.4000/nuevomundo.68233 Lecombe, D. (2014). "Nous sommes tous en faveur des victimes": La diffusion de la justice transitionnelle en Colombie. París: LGDJ, Institut Universitaire Varenne.

Macdonald, S. (1993), Un nouveau “corps des visiteurs": Musées et changements culturels. Culture et Musées 3(1), 13-27. https:/ / doi.org/10.3406/ pumus.1993.1021

Mauss, M. (1921). L'expression obligatoire des sentiments (rituels oraux funéraires australiens). Journal de psychologie, 18, 425-434.

Mesnard, P. (2012). La question du pathos dans les espaces des musées et des mémoriaux. En A. Becker \& O. Debary (Eds.), Montrer les violences extrêmes: Théoriser, créer, muséographier historiciser (pp. 63-95). Grane: Creaphis Editions.

Moura de Oliveira, G., \& Veronese, M. V. (2019). Brasil y el "fenómeno Bolsonaro": un análisis preliminar. Revista Mexicana de Ciencias Politicas y Sociales, 64(237), 245-268. https://doi.org/10.22201/ fcpys.2448492xe.2019.237.68273

Museo Casa de la Memoria. (2020). https:/ / www.museocasadelamemoria. gov.co/elmuseo/mision-del-museo-casa-de-la-memoria-de-medellin/ 
Museo Casa de la Memoria. (2018). Informe de gestión. Medellín: Museo Casa de la Memoria.

Museo de Antioquia. (2017). Informe de gestión. Medellín: Museo de Antioquia. Neumayer, L. (2012). «Dépasser Trianon»: Les transformations du nationalisme hongrois, de la «politique de la nation » à la protection des minorités dans l'UE. Politique européenne, 37(2), 102-131. https://doi. org/10.3917/poeu.037.0102

Oeser, A. (2010). Enseigner Hitler. Les adolescents face au passé nazi en Allemagne: interprétations, appropriations et usages de l'bistoire. París: Éditions de la Maison des Sciences de l'Homme.

Parque Explora. (2018). Revista Parque Explora: cuando la educación significa paz. Medellín: Parque Explora.

Pécaut, D. (1997). De la banalité de la violence à la terreur : le cas colombien. Cultures \&o Conflits, 24-25(1), 159-193. https:/ / doi.org/10.4000/ conflits.2169

Salamanca Villamizar, A. (2015). Los lugares de la memoria y de la acción política en Guatemala. Justicia transicional, políticas del reconocimiento y ficciones de secularismo. Revista de Estudios Sociales, (51), 62-75. https://doi.org/10.7440/res51.2015.05

Sánchez, G. (2014). Territorios de memoria. Revista Arcadia. Recuperado de https://www.revistaarcadia.com/impresa/especial/articulo/territorios-de-memoria/39003

Sánchez, G. (2018). Reflexiones sobre genealogía y políticas de la memoria en Colombia. Analisis politico, 31(92), 96-114. https://doi.org/10.15446/ anpol.v31n92.71101

Sodaro, A. (2017). Exhibiting Atrocity: Memorial Museums and the Politics of Past Violence. New Brunswick: Rutgers University Press.

Valle Flórez, M. M., Giraldo Velásquez, C. M., \& Zapata Aguirre, S. (2018). Museo de Antioquia. Públicos, estrategias y retos. Medellín: Fondo Editorial Remington.

Young, J. E. (1993). The Texture of Memory: Holocaust Memorials and Meanings. New Haven, Londres: Yale University Press.

Wahnich, S. (Ed.). (2011). Fictions d'Europe: la guerre au musée. Allemagne, France, Grande-Bretagne. París: Éditions des Archives Contemporaines. Williams, P. (2007). Memorial Museums: The global rush to commemorate atrocities. Nueva York: Berg Publishers. 


\section{Entrevistas}

Mujer, artista, 40 años, 18 de abril de 2015.

Mujer, enfermera, 28 años, 23 de abril de 2015.

Hombre, estudiante, 21 años, 25 de abril de 2015.

Hombre, ingeniero, 48 años, 25 de abril de 2015.

Hombre y hombre, profesor y estudiante, 25 y 28 años, 25 de abril de 2015.

Hombre, exiliado en Argentina, 35 años, 25 de abril de 2015.

Madre e hija, sin empleo, 82 y 65 años, 26 de abril de 2015.

Hombre y mujer, estudiantes, 18 y 20 años, 26 de abril de 2015. 


\section{Anexo}

Cuestionario sobre los públicos del Museo Casa de la Memoria

En el marco de una investigación doctoral sobre los museos de la memoria en Colombia para la Universidad París Nanterre y a partir del interés del Museo Casa de la Memoria (MCM) de reconocer sus públicos, realizamos la presente encuesta. Este cuestionario es totalmente anónimo y las informaciones recogidas serán utilizadas solo con fines académicos y para la retroalimentación interna de los procesos del Museo.

Le agradecemos su colaboración. Para dejar su contacto o compartir comentarios, puede escribir a xxxxxx@xxxxx. Puede igualmente, agregar sus comentarios y/o su contacto al reverso del cuestionario.

Encierre en un círculo las respuestas que corresponden a su experiencia.

FECHA:

HORA:

\section{1) ¿Cómo se enteró del Museo Casa de la Memoria (MCM)?}

Prensa - Televisión - Radio - Internet - Institución - Familia - Amigos - Trabajo - Otro (precisar):

2) ¿Por cuál(es) razón(es) vino a visitar este espacio?

3) ¿Le contó a alguien que venía al MCM?

Sí_ No

Si su respuesta es SÍ, ¿Quién?: 
4) ¿Después de su visita, recomendaría el MCM a sus conocidos?<smiles>[SiH3]N=[NiH2]</smiles>

¿Por qué?

5) ¿Cuál es la sensación/impresión que tiene después de haber hecho la visita?

6) ¿Diría que el MCM habla de un tema que lo involucra a usted? Sí__ No

¿Por qué?

7) Si tuviera que escoger cuatro elementos de la Sala "Medellín: Memorias de violencia y resistencia" que más lo marcaron (escritos, fotos, instalaciones, videos, etc.), ¿cuáles serían?

8) Dentro de los hombres y de las mujeres mencionados en la exposición, ¿Cuál o cuáles le llamó la atención?

9) Dentro de los hechos relatados en la exposición, ¿Cuál o cuáles le llamó la atención? 
10) ¿Hubo información a lo largo de su visita que nunca había visto? ¿Cuál o cuáles?

11) ¿Hubo información que esperaba encontrar y que no encontró? ¿Cuál o cuáles?

12) ¿Considera que el MCM porta un mensaje?

Sí_ No

Si su respuesta es SÍ, Cuál?:

13) Calificaría su experiencia de visita como (diversas respuestas posibles):

Afectiva / Ciudadana / Conmemorativa / Educativa / Conmovedora / Intelectual / Patriótica / Lúdica / Dramática / Estética / Pérdida de tiempo / Política / Decepcionante / Espiritual / Otra:

14) Diría que el MCM es un espacio (diversas respuestas posibles):

Artístico / Solidario / Cultural / Ciudadano / Pedagógico / Histórico / Conflictivo / Nacional / De reconocimiento / Antioqueño / Conmemorativo / Patriótico / Oficial / Político / Medellinense / Pacifista / Diverso / Otro:

15) ¿Qué temas de interés le puede sugerir usted al MCM? 
16) ¿Qué espacios del Museo Casa de la Memoria visitó?

Sala Central / CRAM / Exposición "La Toma. Memorias y desmemorias de Quebrada Arriba" / Exposición "Video - verónica" / Exposición "Des-Apariciones" / Jardines / Memorial

17) ¿Identificó una dificultad técnica a lo largo de su visita?

Sí_ No

Si su respuesta es SÍ, Cuál?:

18) ¿Vino acompañado/a?

Sí_ No

¿Por quién? (puede señalar varias respuestas)

Hijos / Nietos / Pareja / Padres / Abuelos / otros familiares / Colegas / Suegros / Amigos / Otro:

19) ¿Cuánto tiempo duró su recorrido en la sala?

Menos de 30 minutos / 30 min $-1 \mathrm{~h} / 1 \mathrm{~h}-1 \mathrm{~h} 30$ / 1h30 - 2h / Más

20) ¿Ya había visitado el MCM?

Sí__ No

21) ¿Cuántas exposiciones o museos ha visitado los dos últimos años?

Una / Dos / Tres / Cuatro / Más 
22) ¿Ha visitado otros espacios que abordan el tema del conflicto armado?

Sí, varios / Sí, solo uno / Nunca, esta es la primera vez

23) ¿Piensa visitar próximamente otros espacios que abordan este tema?

Sí_ No

Si su respuesta es SÍ, Cuáles?:

24) ¿Ha leído libros o visto películas, telenovelas o documentales sobre este tema en los últimos dos años?

Sí_ No_

25) ¿Personalmente usted se interesa en la política?

Mucho / Bastante / Poco / Para nada

26) Sobre la escala siguiente, ¿dónde situaría su orientación política? (Respuesta opcional)

Izquierda

Derecha

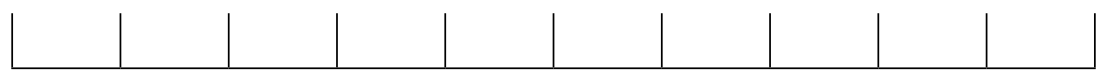

27) ¿Cuál importancia tiene la religión en su vida? (Respuesta opcional)

Ninguna / Poca / Limitada / Grande / Central / Sin respuesta 
Sexo:

$\mathrm{F} / \mathrm{M}$

Año de nacimiento:

Ciudad de nacimiento:

Ciudad de residencia, barrio si vive en Medellín:

Actividad actual:

Si es jubilado(a), última actividad ejercida:

Último diploma obtenido:

¡Muchas gracias por su tiempo!

[Puede dejar comentarios y datos de contacto al reverso] 